\title{
Exploring the Role of the Speech-language Therapist in City Centre Preschools
}

\begin{abstract}
This study investigates the perception of the strengths and challenges that face city centre preschool teachers and preschool learners in the acquisition of English as medium of instruction and to use the results to explore the role of speech-language therapists in this context. A descriptive survey, incorporating a quantitative data collection method, was selected as the research design and a questionnaire was developed as a survey instrument. The findings identified the strengths as including the creative communication strategies employed by the pre-schoolers and the innovative techniques of the teachers. Perceived challenges include a cultural and linguistic mismatch between teachers and learners and communication barriers that cause emotional and behavioural problems in classrooms. The study suggests that speech-language therapists need to consider and employ service delivery models instead of traditional models with the preschool teachers.
\end{abstract}

Keywords: Additional language learners, city centre preschools, English as language of learning and teaching, preschool learners, multilingual schools

Sandra du Plessis, University of Limpopo (Medunsa Campus).

E-mail: sandra.duplessis@ul.ac.za

South African Journal of Childhood Education | 2012 2(2): 94-116 | ISSN: 2223-7674 | ๑ UJ 


\section{Introduction}

The demographics of urban South Africa have changed. An ever-increasing number of preschool learners are attending preschools where the Language of Learning and Teaching (LoLT) is not their home language (L1), but an additional language (L2) (Heugh, 2008). This change has implications for South African speech-language therapists. In the White Paper 5 (RSA, 2001), the Department of Education (DoE) called for collaboration between all professionals involved in Early Childhood Education (ECE) to address, among others, the language needs of young learners. Such collaborative services to preschool learners are in line with global trends in service delivery (Du Plessis, 1998). Although teachers are the most important link in the adjustment process of learners to the classroom (Uys, Van der Walt, Van den Berg \& Botha, 2007), it is accepted that educational support professionals, such as speech-language therapists, need to be included as team members to support learners. Speech-language therapists have to serve this population and make a meaningful contribution to support the learners' language acquisition and education.

Preschool teachers already have a demanding task in preparing pre-schoolers for formal schooling and face numerous challenges when teaching learners not yet proficient in the LoLT. The purpose of this article is to explain the challenges in city centre preschools through the lens of the preschool teacher in order to provide guidelines to speech-language therapists in the exploration of their role in the changed context.

\section{Historical perspective on languages in education in South Africa}

Although South Africa is a young democracy, it has already accomplished the formulation of a language policy that enshrines in its constitution the equality of all the South African languages (Cunningham, 2001; Bosman, 2000; Steyn, 2000; RSA, 1996). Different official languages, however, are used in different contexts (Probyn, 2008; Achugar, Schleppegrell \& Oteìza, 2007; LANGTAG, 1996), and language in education is one such context.

In South Africa, the government and, in some communities, the parents/caregivers and learners have an overwhelmingly positive attitude towards English (Obondo, 2007; De Klerk, 2002a). It is the most frequently used official language in education and is regarded by some as the key to higher education (Cele, 2001). Arguably, English poses the biggest threat to L1 education because of its popularity among parents/ caregivers and learners (Kamwangamalu, 2008; Probyn, 2008). Although many are of the opinion that English should be accepted as the dominant language in education in the interest of equality and democracy, ethical and pedagogical questions arise when so many learners have limited proficiency in English (Probyn, 2008; Soudien, 2007).

In South Africa, English enjoyed prominence during the struggle against apartheid, both politically and ideologically (Kamwangamalu, 2008). English was the working language of the African National Congress (ANC) since its inception in 1912 up to the 
present (Holmarsdottir, 2009). This trend towards English as the preferred language of communication in South Africa is continuing because of its international and commercial benefits. The perception also exists that English is the only means to success because the world of opportunity is essentially English speaking (Probyn, 2008). According to Obondo (2007), the desire for English by some Black/African students is further fuelled by a deep-seated resistance to L1 education. The L1 is stigmatised as inferior and associated with inferior apartheid education and limited employment opportunities, as documented by history (Obondo, 2007).

During Apartheid Black/African education was separated from White education and regulated from 1953 onwards by the Department of Bantu Affairs. Compulsory L1 instruction was introduced to Black/African learners from Grade One and it was stipulated that both Afrikaans and English be taught as subjects. In the senior primary and secondary school years, only Afrikaans and English instruction were allowed in Black/African schools. In 1974, the then province of Transvaal further stipulated that social studies and mathematics be taught in Afrikaans (Lemmer, 1995). Black/ African learners had to master difficult subject content in languages other than their L1. This policy sparked off the Soweto uprising in 1976, resulting in the disruption of education for a whole generation of Black/African learners (Kamwangamalu, 2008; Probyn, 2008). When the government finally reversed this decision under tremendous pressure from the Black/African community, parents/caregivers, for the first time, had the freedom to choose the LoLT for their children from the Fourth Grade. In 1991, the De Klerk government took a step closer to democracy and allowed White government schools to enroll learners of all races, leaving the decision on the LoLT to the parent body of each school (Peirce \& Ridge, 1997). Black/African parents/caregivers were no longer alienated from decision-making in education (Van Wyk, 2010).

Parents/caregivers were overwhelmingly in favour of sudden transfer to English after the fourth year at school (Heugh, 2008). This language model is used in most other sub-Saharan African countries, although there is no evidence that this model leads to successful learning outcomes (Heugh, 2008; Obondo, 2007). This choice to switch to English in grade 4 disregards globally accepted theories that the home language and not the first additional language should be the logical choice as LoLT (Probyn, 2008; Uys et al., 2007). According to the Language in Education Policy (LiEP), South African schools may still choose any of the official languages as the LoLT, but an African language is rarely chosen. In addition, there is no stipulation in policy that requires a transfer from the home language to English as Language of Teaching and Learning (ELoLT) is required at any level (Holmarsdottir, 2009).

A study by De Klerk (2002a) illustrates why English strongly appeals to Black parents/caregivers. De Klerk (2002a) investigated the reason why 194 Xhosa-speaking learners were sent to English schools in the Grahamstown area from their preschool years. The reasons why parents/caregivers in the research project decided to send their children to English schools are summarised in Table 1. 
Table 1: Reasons for placement decision

\begin{tabular}{|c|c|}
\hline $\begin{array}{l}\text { Reason for placement in English- } \\
\text { medium school }\end{array}$ & Expected outcomes \\
\hline $\begin{array}{l}\text { Need for better education in more stable } \\
\text { environment }\end{array}$ & $\begin{array}{l}\text { More meaningful education free from problems in } \\
\text { Black/African schools }\end{array}$ \\
\hline English is the international language & $\begin{array}{l}\text { Learners prepared for modern world with cultural } \\
\text { awareness, tolerance, communication with other } \\
\text { groups }\end{array}$ \\
\hline Need to give learners a better chance in life & $\begin{array}{l}\text { Learners able to be financially better off than } \\
\text { parents/caregivers }\end{array}$ \\
\hline English will open the door to more job opportunities & $\begin{array}{l}\text { Equip learners with competitive edge and ability to } \\
\text { speak the language of the workplace }\end{array}$ \\
\hline English is vital for educational success in general & $\begin{array}{l}\text { Learners able to understand other subjects and pass } \\
\text { future exams in English }\end{array}$ \\
\hline Prestige of English & Higher status of learners able to speak English \\
\hline Social advantages of English & Learners will become assertive and confident \\
\hline $\begin{array}{l}\text { Want learners to be able to mix with English L1 } \\
\text { speakers }\end{array}$ & $\begin{array}{l}\text { Learners must not be embarrassed when speaking } \\
\text { English }\end{array}$ \\
\hline Closer geographical proximity to an English school & $\begin{array}{l}\text { Learners must assimilate into English-speaking } \\
\text { Western culture }\end{array}$ \\
\hline
\end{tabular}

Source: De Klerk (2002a).

According to Table 1, the parents/caregivers wanted their children to master English. The parents/caregivers based their decision on the overwhelming approval by family members (42\%) and teachers (24\%), as opposed to only $8 \%$ of the parents/caregivers who reported that people tried to persuade them against enrolling the learners in English schools. Not only access to English, but also more resources, healthier learnerteacher ratios, as well as better learning opportunities at these schools formed part of the parents'/caregivers' motivation for selecting English schools for their children (Probyn, 2008; De Klerk, 2002a).

The South African history cannot be undone, but it is clear that the country's language policies complicated the provision of education in the past. Currently, the core ideological aims of democracy, racial tolerance, human rights, and peaceful conflict resolution enshrined in the South African constitution are guiding educational reform, and emerging educational policies aim to rectify the wrongs of the past and focus on the needs of society (Le Grange, 2002; Cele, 2001; Gumbo, 2001; RSA, 1996).

\section{The urban school context}

In 1991, a few years before the end of the Apartheid era, the former White governmental schools in South Africa started to accept learners from all races. The South African Schools Act (Act no 37 of 1997) formalised the process of desegregation 
of schools, after which learners were no longer admitted to schools according to racial classifications (Van Wyk, 2010; Vandeyar, 2010). The desegregation of schools and the freedom of movement after apartheid resulted in a demographic shift of Black/African learners to urban ("White") schools. Many parents/caregivers chose to place their children in English schools, some on the basis of the belief that time on task will aid their children to reach high levels of proficiency in English (Hornberger \& Vaish, 2009; Probyn, 2008). However, $80 \%$ of Black/African learners remained in rural or township schools (Probyn, 2008).

With the migration of Black/African learners to formerly White schools many teachers in urban English schools in South Africa were caught off guard by the diverse language situation in their classrooms (Barkhuizen, 1993). The rapid political and demographic changes of the following few years forced these teachers to adapt to new situations, which often impacted on their identities, beliefs and value systems (Vandeyar, 2010; Peirce \& Ridge, 1997). Two decades ago it already became apparent that the sudden and abrupt transition from the learners' L1 to English was a major problem that all teachers needed to address, as many learners were not yet proficient in English when enrolled in English schools.

Vandeyar (2010) has found that two thirds of participant teachers studied have attempted to assimilate learners from diverse cultural groups into the hegemonic culture of the mostly "White" urban schooling in South Africa. In other words, they are teaching from a particular cultural lens without any attempt to create a sense of belonging for the Black/African learners. These teachers have responded to the desegregation of schools with assimilation and pseudo colour blindness, the latter indicating that teachers suppress negative images held of learners by professing not to see colour (Vandeyar, 2010). The cultural background of every learner in a diverse classroom needs to be incorporated into lessons (Vandeyar, 2010; Driscoll \& Nagel, 2002). ${ }^{1}$

\section{Role-players in language acquisition in the city centre preschool context}

Currently many Black/African learners, who are not proficient in English, are being placed in city centre English preschools. The parents/caregivers of these learners often rely on teachers to play a leading role in teaching their children English in preparation for primary school (Uys et al., 2007). It is generally accepted that, during the preschool years, parents/caregivers and teachers are the main role-players in the learners' education, because of the amount of time that learners spend in either the home or school environment. The White Paper 5 (RSA, 2001) states that the responsibility for the care and upbringing of young children belongs to parents or families (caregivers),

1 An interesting report from the Minister of Education of Eritrea, where the indigenous languages are the LoLT, indicated that the most important achievement of this education policy was the unshakable confidence and self-esteem observed in their learners (Mohammed, in Obondo, 2007). 
which directly implicates their involvement as primary role-players in the support of their children's language acquisition.

Preschool teachers are viewed as the second major role-players in the support of preschool learners' acquisition of the home language, or the LoLT. As learners spend many of their waking hours with teachers, their experiences under the guidance of the teachers will have an impact on the learners' social, emotional, cognitive and language development (NAEYC, 1996).

Preschool teachers have special knowledge, acquired through training, of education in early childhood. They are also knowledgeable about preschool learners through continuous observation and can assess learners in natural situations (Du Plessis, 1998). The question arises whether these abilities are sufficient to teach in the current South African situation where schools have become multilingual, and where preschool teachers face the predicament of teaching in English, while they know that all learners will not fully comprehend the content of their teaching.

More and more demands at all levels are made of South African preschool teachers (Cunningham, 2001). Preschool teachers are expected to have sophisticated knowledge of subject matter and a wide repertoire of teaching strategies. Moreover, they need to be familiar with theories of learning and cognition, knowledge of pedagogy and curriculum, and competence with technology and assessment. The South African context requires preschool teachers to understand multiple languages, as well as socio-cultural and developmental backgrounds (Viljoen \& Molefe, 2001). It is clear that multilingual classrooms may present a challenge to teachers as it adds to existing demands.

Although ASHA (ASHA, 1998; ASHA, 1983) issued a position statement in 1983, clarifying the association's viewpoint on speech-language therapists' role when serving multilingual clients in the USA, the South African Speech-Language and Hearing Association (SASLHA) only published guidelines regulating local speechlanguage therapists' intervention with learners acquiring an L2 20 years later (SASLHA, 2003). These guidelines clearly indicated that speech-language therapists need to get involved in the acquisition of a second language.

Speech-language therapists have the training and knowledge to assist preschool learners in acquiring language-learning skills in the LoLT. Since home language and second language development, assessment, and intervention are acknowledged professional functions of speech-language therapists, it is widely accepted that they are the ideal educational support professionals to intervene in the process of language acquisition (Ehren \& Whitmire, 2005). Apart from understanding the nature of language and the interaction between a child and his or her environment, a comprehensive knowledge of language development in young children and intervention strategies to facilitate the process of language acquisition provide speech-language therapists with the expertise to offer focused language stimulation (Jordaan, 1993). Speech-language therapists can make a contribution as one of the team members to support language learning, even without being proficient in the learner's L1, because they are familiar 
with language acquisition methodologies and knowledge of language acquisition. In addition, speech-language therapists' involvement with preschool learners may stimulate important collaboration between the professions of the speechlanguage therapist and the preschool teacher (Ehren \& Whitmire, 2005; Du Plessis \& Naudé, 2003).

The linguistic needs of the pre-schooler in urban South Africa - to acquire full proficiency in L1, as well as the LoLT - need to be addressed by all role-players. The first language has to be promoted, maintained and developed in order to ensure that the acquisition of the first additional language is an additive rather than a subtractive process (Du Plessis \& Louw, 2008). Such proficiency would enable the learners to increase their communication skills and cognitive flexibility in a multilingual environment. L1 acquisition usually proceeds smoothly for most learners in the preschool years (Jordaan, 1993), but all learners do not always acquire the LoLT effortlessly. Role-players may need to intervene in ways that stimulate and support language development, always taking into account the specific and unique needs of the preschool learner and the South African educational system.

If teachers are familiar with the unique characteristics and needs of learners, they may construct a classroom context accommodating these needs (Cele, 2001). Preschool teachers may create a learning environment that provides conditions for support and creates a challenge to their learners - a positive learning environment for education and learner motivation.

To respond effectively to the language acquisition challenges of learners not yet proficient in the LoLT (English), as well as their personal challenges in facilitating the acquisition of this language, a group of preschool teachers in a specific city centre multilingual context requested advice and support from speech-language therapists. The research reported here was initiated in response to this request.

\section{Method}

The purpose of this study was threefold:

- To determine the perceptions and opinions of preschool teachers regarding the strengths of, and challenges to, preschool learners acquiring English as an additional language.

- To determine the strengths of, and challenges to, preschool teachers regarding their role in facilitating communication development in preschool learners that are in the process of acquiring English.

- To explore the support role of speech-language therapists in facilitating the acquisition of English.

A descriptive survey research design, implementing the quantitative research method, was selected for the purpose of this study. Permission to conduct the research was obtained from the Research Ethics Committee of the Faculty of Humanities 
at the University of Pretoria. In addition, approval was obtained from the Gauteng department of education (GDE) and informed consent from the principals and teachers at the participating schools. The ethical considerations of protection from harm, informed consent, right to privacy and honesty with professional colleagues were emphasised and adhered to.

\section{Context}

All preschools had to fall in a specified geographical area in a selected city centre. The specific city centre underwent a radical change in population composition, because of the political changes in South Africa since 1994. The former exclusively White population in the city centre changed to a racially desegregated population when many people from the Black/African communities moved into this area.

\section{Participants}

All preschool teachers at the nine identified preschools in the context gave consent to participate in the study. Participants were selected because of their accessibility and willingness to participate in the research, irrespective of training and experience. Questionnaires were sent to 36 teachers and 32 returned the questionnaires yielding a response rate of $88 \%$.

\section{Material}

A self-designed questionnaire was compiled as survey instrument. The questionnaire enabled the author to gain insight into the first-hand experiences of preschool teachers who were in their current teaching position involved with preschool learners acquiring the LoLT, which was English. The strength of such a survey instrument was that it yielded information on the existing situation and the participants' feelings and perceptions. The questionnaire was judged and found to be appropriate by an expert lecturer in the discipline of Speech-Language Pathology, specialising in childhood language development. In addition, a pre-test was conducted for face validity and to finalise the content. Four preschool teachers from four different preschools in the city centre were randomly selected to form a trial group of pre-test participants. The data analysis was also confirmed as correct by an independent rater.

The questionnaire was divided into ten sections, namely demographic information, exposure of the teachers to multilingual classes, general observations of the teachers regarding the learners, information on the learners' vocabulary development, information on the learners' syntactic abilities, information on the learners' pragmatic skills, strategies to support the learner, teachers' general beliefs on language development, teachers' need for training and an open question. Participants were asked to respond according to the Lickert type scale. The number of response categories was respectively two, three and four and was alternated in the questionnaire to prevent bias (Delport \& De Vos, 2002). Open-ended questions were included to allow participants to comment freely and to afford the author 
the opportunity to collect information that might have been omitted from the questionnaire. The majority of the questions were close-ended, which shortened the duration for completion.

\section{Data collection}

The questionnaires and informed consent forms were delivered to the principal of each preschool with a cover letter explaining the purpose of the research and providing guidelines for the completion of the questionnaire. Participants had two weeks to complete the questionnaire. The researcher collected the completed questionnaires after two weeks.

\section{Data analysis}

Since the nature of the research was exploratory, descriptive and contextual, descriptive statistics (Leedy \& Ormrod, 2005) were used to describe the data and illustrate trends within the research context. Statistical computations, such as frequency distributions, were employed to provide an indication of the perceptions of the teachers.

\section{Results and discussion}

\section{Description of preschool teachers}

The results demonstrated in Table 2 emphasise that the selected characteristics of teachers did indeed add to the complexity of the teaching situation in the research context. The analysis of these characteristics provided an indication of some of the personal challenges encountered by preschool teachers.

According to Table 2, most of the teachers (84\%) were Afrikaans speaking, but they were teaching mostly in English, which is not their L1, with only $10 \%$ of the teachers having English as the home language. When considering that all participating preschools had English as their LoLT, it is clear that the majority of the teachers were not teaching in their home language. Afrikaans is the language of the majority of the White population in the province where the research was conducted (Census in Brief, 2001), which may explain why the majority of the teachers had Afrikaans as their L1.

From some of the teachers' responses to the open question it became evident that all may not be fully proficient in English. As numerous authors, including Nel \& Müller (2010), Cele (2001), Cunningham (2001), Barkhuizen (1993) and Macdonald (1991), have voiced their concerns about the English proficiency of South African teachers, a question arises about the English skills of the teachers in this study. If some teachers were indeed not fully proficient in English, the teaching situation could be complicated, as limited English language skills may inhibit conversational exchanges in the classroom. Exposure to a less than ideal model of English may influence learners' acquisition of English negatively (De Klerk, 2002b). 
Table 2: Profile of teachers $(\mathrm{N}=32)$

\begin{tabular}{|c|c|c|c|}
\hline Characteristics & Description & $\begin{array}{c}\text { Number of } \\
\text { teachers }\end{array}$ & $\begin{array}{c}\text { Percentage of } \\
\text { teachers }\end{array}$ \\
\hline Home language & $\begin{array}{l}\text { Afrikaans } \\
\text { English } \\
\text { Sesotho } \\
\text { isiZulu }\end{array}$ & $\begin{array}{c}27 \\
3 \\
1 \\
1\end{array}$ & $\begin{array}{c}84 \% \\
10 \% \\
3 \% \\
3 \%\end{array}$ \\
\hline $\begin{array}{l}\text { Additional } \\
\text { languages spoken* }\end{array}$ & $\begin{array}{c}\text { English } \\
\text { Afrikaans } \\
\text { Sesotho } \\
\text { German } \\
\text { isiZulu } \\
\text { isiXhosa } \\
\text { Sepedi } \\
\text { Siswati } \\
\text { Xitsonga } \\
\text { Dutch } \\
\text { Sign language }\end{array}$ & $\begin{array}{c}28 \\
5 \\
3 \\
2 \\
1 \\
1 \\
1 \\
1 \\
1 \\
1 \\
1 \\
\end{array}$ & $\begin{array}{c}87 \% \\
15 \% \\
10 \% \\
6 \% \\
3 \% \\
3 \% \\
3 \% \\
3 \% \\
3 \% \\
3 \% \\
3 \% \\
\end{array}$ \\
\hline $\begin{array}{l}\text { Language } \\
\text { preference }\end{array}$ & \begin{tabular}{|c} 
Not provided \\
Afrikaans \\
English \\
Afrikaans and English
\end{tabular} & $\begin{array}{c}1 \\
26 \\
3 \\
2\end{array}$ & $\begin{array}{c}3 \% \\
81 \% \\
10 \% \\
6 \% \\
\end{array}$ \\
\hline $\begin{array}{l}\text { Teaching } \\
\text { experience with } \\
\text { multilingual classes }\end{array}$ & $\begin{array}{l}\text { Not provided } \\
1 \text { year } \\
2 \text { years } \\
3 \text { years } \\
4 \text { years } \\
5 \text { years } \\
6 \text { years } \\
7 \text { years } \\
10 \text { years } \\
17 \text { years } \\
21 \text { years }\end{array}$ & $\begin{array}{l}1 \\
5 \\
3 \\
4 \\
6 \\
3 \\
3 \\
3 \\
2 \\
1 \\
1\end{array}$ & \begin{tabular}{|c|}
$3 \%$ \\
$15 \%$ \\
$10 \%$ \\
$12 \%$ \\
$18 \%$ \\
$10 \%$ \\
$10 \%$ \\
$10 \%$ \\
$6 \%$ \\
$3 \%$ \\
3
\end{tabular} \\
\hline
\end{tabular}

*Some teacher participants listed more than one additional language.Adapted from Du Plessis and Louw (2008)

The fact that the overwhelming majority of teachers were White indicated that teachers kept their positions in the city centre, while the population in this area became racially desegregated. This may also be the result of previous limited opportunities in higher education for Black/African learners resulting in a shortage of Black/African preschool teachers. In contrast to the increasing learner diversity, there is a lack of diversity among the teaching staff. While Black/African learners have migrated to city centre schools, the profile of the teachers has remained relatively unchanged, resulting in a linguistic and cultural mismatch between the teachers and a large number of the learners (Vandeyar \& Killen, 2006). These teachers have to be cautious not to allow learners to view themselves through their "White" cultural lens, but rather create a sense of belonging to the Black/African learners. 


\section{Description of preschool learners}

Table 3: Language data for 760 pre-schoolers as recorded by 32 teachers

\begin{tabular}{|l|c|c|}
\hline \multicolumn{1}{|c|}{ Home language } & Number of learners & $\begin{array}{c}\text { Percentage of } \\
\text { learners }\end{array}$ \\
\hline Unknown to teacher & 281 & $36,9 \%$ \\
\hline Afrikaans & 198 & $26 \%$ \\
\hline Sesotho & 76 & $10 \%$ \\
\hline English & 72 & $9,5 \%$ \\
\hline Setswana & 50 & $6,6 \%$ \\
\hline isiXhosa & 20 & $2,6 \%$ \\
\hline Sepedi & 19 & $2,5 \%$ \\
\hline isiZulu & 17 & $2,2 \%$ \\
\hline Other specified African languages & 9 & $1,2 \%$ \\
\hline Tshivenda & 4 & $0,5 \%$ \\
\hline Other unspecified African languages & 3 & $0,4 \%$ \\
\hline French & 3 & $0,4 \%$ \\
\hline Seswati & 2 & $0,3 \%$ \\
\hline Xitsonga & 2 & $0,3 \%$ \\
\hline isiNdebele & 2 & $0,3 \%$ \\
\hline Portuguese & 2 & $0,3 \%$ \\
\hline Total & 760 & $100 \%$ \\
\hline
\end{tabular}

Reprinted: Du Plessis and Naudé (2003).

Table 3 provides details of the L1 of the preschool learners in the nine preschools in the specific city centre. In all of the 32 participating classes, most of the learners (90,5\%) were L2 learners in preschools with English as the LoLT. The preschool teachers in the study had to cope with English L1 and ELoLT learners in the same classroom and had to teach learners of whom all were not yet proficient in the LoLT. This trend is typical in the South African educational context, as has also been pointed out by Dawber and Jordaan (1999) and Barkhuizen (1993) and implies that a situation thus exists where preschool teachers have to teach on different language levels to individual learners in the same classroom.

An alarming fact revealed in Table 3 is that the L1 of a large number of preschool learners $(36,9 \%)$ was unknown to the teachers. It should be acknowledged that the identification of the principal L1 may have been hampered by some learners speaking more than one language at home, while multiple languages were represented in the classrooms (Sadiki, 2002). The fact that the teachers could not recognise the L1 of such a large number of learners may indicate that the teachers could also not identify 
the cultural background of the learners, as language is considered to be the bearer of culture (Smit, 1993). The importance of being aware of the cultural background of learners is emphasised in the literature (Vandeyar, 2010) and is recognised as part of cultural competence. If the teachers were unaware of the $L 1$ and cultures of the learners, they might not have been able to create a sense of belonging for their learners, which would result in a classroom atmosphere representative of the hegemonic culture of the school (Vandeyar, 2010).

The results show that all eleven official languages were represented in the research context. This is in contrast with the situation in the rural areas where dominant official languages can often be identified (Census in Brief, 2001) and L1 education could more readily be implemented. The use of English as LoLT to accommodate learners with diverse L1s may indeed offer a practical solution in this city centre context.

\section{Preschool learners' coping strategies}

According to the results the majority of teachers (84\%) indicated that code-switching and code-mixing were often used as coping strategies by the learners. In all the preschools in the research context, 50\% or more of the learners in any class found it difficult to express themselves only in English and reverted to their $L 1$ to facilitate comprehension. Probyn (2008) observed that code-switching often occurred in South African classrooms where many learners are from multilingual backgrounds. It appeared that learners drew on their language resources by code-switching, using it as a communication strategy (SASHLA, 2003). It is argued that multilingual learners may be using their $\mathrm{L} 1$ to assist understanding and communicating in the context within which the language is used. The code-switching by multilingual learners was not a case of confusing languages, but typical of L2 acquisition. Although many teachers may regard code-switching as undesirable, the literature reflects the view that codeswitching is normal, useful and widely used in the discourse of multilingual speakers (Probyn, 2008). Teachers should accept code-switching as typical behaviour and may use it as a resource in teaching.

The results also indicate that the teachers observed that the majority of the learners used gestures when communicating in English. The use of gestures as strategy to facilitate comprehension is a common phenomenon during the non-verbal phase of $L 2$ acquisition (Roseberry-McKibbin \& Brice, 2000), as the learner often listens and focuses on understanding the L2. It is a phase of active observation and rehearsal or sound experimentation, usually done quietly. Gestures should be viewed as normal behaviour and not as a cause for concern during the initial phases of the acquisition of an L2.

The fact that the preschool learners showed typical patterns of L2 acquisition and employed creative communication strategies may therefore be regarded as strengths. 


\section{Socio-emotional behaviour observed}

According to the results a large percentage of the teachers often observed negative social or emotional behaviour (such as withdrawal 60\%, frustration $60 \%$, discipline problems $45 \%$, and not volunteering to answer $67 \%$ ) that could be associated with poor L2 skills. These teachers perceived language proficiency as influencing school performance and social behaviour significantly.

Research has highlighted that learners not yet fully proficient in the LoLT are at risk of developing social problems in the classroom. Crutchley, Botting \& ContiRamsden (1997) reported that, although monolingual and multilingual learners arrived at schools with no emotional and behavioural differences, over time L2 learners developed and exhibited more emotional and behavioural problems than L1 learners. The same perceived negative kinds of behaviour as found in the current research were reported by Viljoen \& Molefe (2001), who observed frustration and discipline problems in South African L2 learners. Fujiki, Brinton, Isaacson \& Summers (2001) found that L2 learners displayed more withdrawal and aggressive behaviours than other learners. Viljoen \& Molefe (2001) observed that many of these negative behaviours were not present on the playground where learners interacted in their L1 with peers from their own culture. These findings were supported by Probyn (2008), which verifies that communication barriers in the classroom, caused by poor L2 proficiency, contributed to a large extent to learners' emotional and behavioural problems. Behavioural problems in these learners therefore may need to be understood against the background of emotional uncertainty as a result of language and cultural differences between the home and school.

\section{Strategies employed by teachers}

The teachers were requested to indicate which strategies they employed to facilitate comprehension and participation for preschool learners. An open question was included in this section of the questionnaire to allow teachers to include techniques not listed, thus preventing bias from limited possibilities. The results are presented in Table 4 .

Table 4 indicates that, apart from planning their lessons, teachers had to plan techniques to convey meaning. By employing their creative skills, learners were provided with opportunities to learn and participate in programme activities. Most of the strategies were verbal, but non-verbal strategies, such as gestures and bodily movements as cues to facilitate comprehension, were also employed to support communication. The fact that the preschool teachers used innovative techniques and developed their own strategies to facilitate comprehension may be regarded as strengths. 
Table 4: Strategies employed by teachers in relation to their teaching with multilingual classes $(\mathrm{N}=32)$

\begin{tabular}{|c|c|c|c|c|c|c|c|c|}
\hline \multirow{3}{*}{ Strategies } & \multicolumn{8}{|c|}{ Teaching experience with multilingual classes } \\
\hline & \multicolumn{3}{|c|}{$\begin{array}{l}\text { 1-5 Years } \\
(\mathrm{N}=21)\end{array}$} & \multicolumn{3}{|c|}{$\begin{array}{c}\text { 6-10 Years } \\
(\mathrm{N}=8)\end{array}$} & \multicolumn{2}{|c|}{$\begin{array}{c}10+\text { Years } \\
(\mathrm{N}=2)\end{array}$} \\
\hline & Often & Seldom & Never & Often & Seldom & Never & Often & Seldom \\
\hline Simplify/rephrase & 19 & 2 & 0 & 7 & 1 & 0 & 2 & 0 \\
\hline $\begin{array}{l}\text { Repeat } \\
\text { instructions }\end{array}$ & 21 & 0 & 0 & 7 & 1 & 0 & 2 & 0 \\
\hline $\begin{array}{l}\text { Accentuate } \\
\text { keywords }\end{array}$ & 21 & 0 & 0 & 7 & 1 & 0 & 2 & 0 \\
\hline $\begin{array}{l}\text { Repeat new } \\
\text { vocabulary }\end{array}$ & 20 & 1 & 0 & 7 & 1 & 0 & 2 & 0 \\
\hline Additional visuals & 20 & 1 & 0 & 6 & 2 & 0 & 2 & 0 \\
\hline Speak slower & 16 & 4 & 1 & 7 & 0 & 1 & 2 & 0 \\
\hline $\begin{array}{l}\text { Repeat learners' } \\
\text { utterances }\end{array}$ & 6 & 7 & 8 & 5 & 1 & 2 & 1 & 0 \\
\hline $\begin{array}{l}\text { Expand learners' } \\
\text { utterances }\end{array}$ & 8 & 6 & 7 & 7 & 1 & 0 & 1 & 0 \\
\hline Use gestures & 14 & 4 & 3 & 7 & 0 & 1 & 2 & 0 \\
\hline Mime & 15 & 5 & 1 & 7 & 0 & 1 & 2 & 0 \\
\hline $\begin{array}{l}\text { Involve parents/ } \\
\text { caregivers }\end{array}$ & 4 & 6 & 11 & 4 & 3 & 1 & 1 & 1 \\
\hline Adapt lesson plan & 3 & 3 & 15 & 7 & 0 & 1 & 1 & 1 \\
\hline $\begin{array}{l}\text { *Intentional } \\
\text { misrepresentation }\end{array}$ & & 0 & & & 1 & & & 0 \\
\hline $\begin{array}{l}\text { *Stories, songs, } \\
\text { rhymes }\end{array}$ & & 21 & & & 7 & & & 2 \\
\hline $\begin{array}{l}\text { *Translate to } \\
\text { learners' L1 }\end{array}$ & & 2 & & & 0 & & & 0 \\
\hline *Dramatizing & & 0 & & & 0 & & & 2 \\
\hline $\begin{array}{l}\text { * Learners as } \\
\text { translators }\end{array}$ & & 0 & & & 2 & & & 0 \\
\hline $\begin{array}{l}\text { *Assistants as } \\
\text { translators }\end{array}$ & & 2 & & & 2 & & & 1 \\
\hline $\begin{array}{l}\text { *Individual } \\
\text { sessions }\end{array}$ & & 2 & & & 0 & & & 0 \\
\hline
\end{tabular}

*Responses to open question

An interesting trend revealed in Table 4 is that overall only a small number of the teachers repeated and expanded the learners' utterances. Whereas the majority 
of teachers, with more than six years' experience with multilingual classes, used these two verbal strategies often, the teacher participants with less than six years' experience did not employ these strategies as a rule. The teachers with less multilingual experience may be unaware of the value of such strategies. This possibility questions their effective use of verbal strategies, as there is strong indication in the literature (Owens, 2008) that imitation, repetition, and expansion of words and phrases are central to the language-learning process and facilitate general language growth. Adult responses facilitate linguistic development by maintaining or adding to the semantic content of what the learner says, while also highlighting structural aspects of language.

The preschool teachers in the research context may benefit from information on naturalistic language facilitation techniques to make instructional input comprehensible to learners with diverse levels of English proficiency.

Upon further analysis of the results the same pattern emerged with the strategy of adapting lesson plans. The majority of teachers with less than six years' multilingual experience never adapted lesson plans, as opposed to the teachers with more multilingual experience who often adapted lesson plans. It appears that the latter group of teachers may be more flexible in their approach, viewing learner-directed activities as educational opportunities even in an organised framework. Adaptability is also advocated by Manolson (1992) who pointed out that adults need to be responsive partners and allow learners to lead in language-acquisition activities.

Table 4 indicates that nine teachers employed some form of code-switching (two translate to learners' L1 themselves; two use peer tutors; five use assistants as translators). Only a small number of the teachers were using code-switching as a resource. The use of code-switching and peer-tutoring has been reported in the literature and holds great potential as technique and strategy to facilitate comprehension in ELoLT learners (Probyn, 2008; Viljoen \& Molefe, 2001). Codeswitching in the classroom may lead to better understanding and communication with L2 learners and prevent communication breakdown between teachers and learners. It does pose a challenge to the teachers in the research context where all 11 official languages were represented. However, it is argued that teachers need to be guided to explore and appreciate the functions of these strategies, drawing on sources already available to them.

\section{Support needs of preschool teachers}

To establish the support required, the teachers' perception of their own support needs was explored. According to the results the teachers were willing to accept support regarding $\mathrm{L} 2$ learners in their classrooms. It is interesting to note that the majority of the teachers (88\%) preferred workshops to formal training, which may be an indication of the amount of time and money the teachers were prepared to spend on acquiring the appropriate knowledge and skills. It may also indicate their preference for the interactive manner of teaching and learning often prevailing at workshops (Du Plessis \& Louw, 2008). 
The responses of teachers indicated their willingness to share responsibilities regarding the support of $L 2$ learners with other knowledgeable professionals. In the results two components of teamwork, namely consultation (advice on how to handle the multilingual learner) and collaboration (assistance by speech-language therapists in planning language lessons and evaluating the language needs of multilingual learners) were indicated as perceived support needs. Based on these results the role of the speech-language therapist as team member of the education support team is discussed forthwith.

\section{The role of the speech-language therapist}

The teachers' perceptions provided valuable information on the challenges to preschool learners not yet proficient in the LoLT, with strong pointers for the provision of a responsive learning environment. As the learners' challenges and strengths did not fall into neat categories, interdisciplinary partnerships may have to be established to bring together different perspectives and expertise for intervention. This presents a challenge to all teachers and educational support professionals. The onus is to form partnerships and to share knowledge and skills related to the learners' strengths and challenges, working collaboratively to enhance the learning process.

Preschool teachers may feel challenged when attempting to meet all these expectations. The greatest challenges emerging from the research results appear to be first, the need for knowledge, and second, the need for support. However, challenges provide opportunities, one of which is to form partnerships in problem solving. In such partnerships speech-language therapists would have to be sensitive to the unique needs of preschool teachers and strive to provide teachers with the information and support they need.

The teachers' need for support clearly indicated that the principle role of the speech-language therapists needs to be indirect, providing mainly consultative, but also collaborative support. Such collaboration may, however, depend largely on the competencies of the preschool teachers and the speech-language therapists in clarifying and redefining their roles to form a team that provides services to the multilingual learners.

The proposed service delivery model to support the acquisition of the LoLT has three components, namely consultation, collaboration, and collaborative intervention.

The first consultative role for both the speech-language therapists and the preschool teachers is professional education or skills development. The preschool teachers may need instruction in the nature of language and communication, whereas the speech-language therapists may need information on the nature of the curriculum and its associated language demands. It may be necessary for the preschool teachers to familiarise the speech-language therapists with the learning areas of the curriculum, enabling them to understand their role within the curriculum and develop appropriate skills and knowledge to work within the curriculum (Struthers \& Lewis, 2004). It implies that both professionals need to become on-going learners themselves, sharing 
knowledge and information, while drawing on the strength of the other in order to gain competencies and provide services responsive to the unique needs of the preschool learner.

The second consultative role identified from the research results involves the designing of learning programmes and the planning of structured language support in classroom activities. The teachers recognise the importance of language to the learners' academic success and socialisation, but they need support to address the learners' linguistic needs. In consultation, the preschool teachers and the speechlanguage therapists need to plan a language-focused curriculum, using the natural contexts of the classroom as point of departure and the classroom format and curriculum as sources of programme content (Giangreco, as cited by Prelock, 2000). The speech-language therapists and the preschool teachers may create a plan of action for addressing the learners' particular language needs, based on what could practically be implemented in the classroom. Such a collaborative approach allows for the synthesising and generalisation of communication skills across contexts and also supports accessibility to the curriculum. The preschool teachers need to play a leading role in any modifications to the curriculum to facilitate comprehension, ensuring that the conceptual requirements of the learning area are met. The speech-language therapists in collaborative curriculum design need to analyse the curriculum to identify important concepts and associated language components (Lazar, 1994), and suggest modifications to the important LoLT input of the preschool teachers.

The first collaborative role of the speech-language therapists, identified from the results, is to assume primary responsibility in the team for coordinating the communication assessment of preschool learners (Ehren, Montgomery, Rudebusch \& Whitmire, 2009). The preschool teachers may take secondary responsibility for the communication assessment, thereby establishing an integrated view of the learners' language abilities (Laing \& Kamhi, 2003). In such interdisciplinary appraisals of the learners' language proficiency, the speech-language therapists need to assume responsibility for collecting, analysing and synthesising the language assessment information, as well as presenting the results to the team (ASHA, 1991). Owing to the preschool teachers' involvement and support in assessing the learners their confidence, skills and knowledge about communication assessment will increase, while the speech-language therapists will acquire knowledge about the nature of the language demands of the curriculum and the multilingual preschool learners' ability to handle these demands.

The second collaborative role in lesson planning or intervention planning, which a critical procedure in successful communication intervention (Wilcox \& Shannon, 1996), It is suggested that the preschool teachers need to assume primary responsibility for planning the curriculum goals and the speech-language therapists for planning the communication goals. In this manner their mutual perspectives on desired outcomes may be combined in intervention planning (Ehren, et al., 2009).

Collaborative intervention is the third role of the speech-language therapists and the preschool teachers, identified from the research results. The role of the 
speech-language therapists in collaborative intervention needs to be a direct role, which implies direct contact with the preschool learners, as well as shared responsibilities with the preschool teachers for direct instruction of the preschool learners (Ehren, et al., 2009). A service delivery model needs to be negotiated between the speech-language therapists and the preschool teachers, and the level of role release between these professionals needs to be determined.

It is suggested that the proposed service delivery model may be an effective approach to providing a supportive intervention to preschool learners who are not fully proficient in English. The first benefit to the learners may be the integration of education and support services so that, through the sharing of information among the preschool teachers and the speech-language therapists, learners with linguistic barriers to learning may be accommodated in inclusive classrooms (Lewis, 2004). Second, through joint curriculum planning and intervention, the learners may benefit in all the learning areas (Lewis, 2004). Third, the multilingual learners may benefit from integrated language instruction as opportunities to expand their language skills may be utilised across the curriculum, providing increased opportunities for LoLT stimulation and acquisition (Lewis, 2004). The fourth benefit to the multilingual learners may be that LoLT skills could be facilitated outside the therapeutic situation and generalised to natural communication settings, such as the classroom and home setting (Hadley, Simmerman, Long \& Luna, 2000)

In conclusion, it is suggested that the speech-language therapists have a consultative and collaborative role to play in the acquisition of the LoLT. However, the role of the speech-language therapists needs to be primarily an indirect role that extends to resource sharing and support of the preschool teachers. In the proposed service delivery model to facilitate the acquisition of LoLT in the research context, the preschool teacher and the speech-language therapist need to support the educational context for instruction together.

\section{Limitations}

A limitation of the research is that the question evaluation by participants during the pre-test did not reveal all the limitations of the questionnaire. The rating scales selected by the pre-test participants in two sections may not have been appropriate for the type of question asked. One could argue that a pre-test with a larger and more representative sample of pre-test participants potentially could provide more opportunities to identify difficulties in the questionnaire. Another limitation is that the research involved a single context and the results could not be generalised.

\section{Conclusion}

Up to now role-players and decision-makers in multilingual education in South Africa were not sensitive to the needs of the teachers, which resulted in policy and planning to be a top-down political process (Obondo, 2008). Some teachers believe that the multidimensional nature of multilingualism may have been oversimplified, 
underestimated and obscured by ideological rhetoric (Lemmer, 1995). In addition, people at grass-roots level, such as teachers, applied linguists, researchers, educational support professionals, had little involvement in language policy decisions (Obondo, 2008). What is further needed is that decision-makers should understand that speechlanguage therapists can help learners to succeed in their education (Ehren \& Whitmire 2005). The results of the current study added to the growing awareness that education needs to be based on a holistic approach to challenges, and that interdisciplinary partnerships need to be established to bring together diverse perspectives and expertise for collaborative decision-making.

Speech-language therapists in South Africa are increasingly being called on to provide services to learners with a L1 different from the LoLT - a call for service that is legitimate. To accelerate the acquisition of the LoLT in preschool learners, speechlanguage therapists need to move beyond the traditional models of service delivery, and expand and release their professional roles across disciplinary lines, as has been recommended in the literature for the past two decades and practised elsewhere in the world. While South Africa is in the process of building an inclusive education system, speech-language therapists are urged to work in collaboration with preschool teachers as a team to provide preschool learners with a solid foundation in L1 and the LoLT for lifelong learning and development. Speech-language therapists need to expand their role into the preschool classroom and engage in a mutual process of sharing their knowledge and skills with others, and learning from others.

“Challenging SLPs [speech-language pathologists] to 'Make it so', requires that they take responsibility for their own destiny and not wait for others to make the necessary changes" (Ehren \& Ehren, 2001, p. 237).

\section{Acknowledgements}

The author wishes to express her gratitude to Emeritus Prof Brenda Louw, previously from the University of Pretoria, for earlier contributions to the research.

\section{References}

Achugar, M., Schleppegrell, M. \& Oteìza, T. (2007). Engaging teachers in language analysis: A functional linguistic approach to reflective literacy. English Teaching: Practice and Critique, 6(2), 8-24.

ASHA, (1983). Social dialects. ASHA, 25(9), 23-24.

ASHA, (1998). Provision of English-as-a-second-language instruction by speechlanguage pathologists in school settings. ASHA, Spring 1998, suppl 18,24-27.

ASHA, (1991). A model for collaborative service delivery for students with languagelearning disorders in the public school. ASHA, 33 (suppl. 5), .44-50.

Barkhuizen, G.P. (1993). Introducing language across the curriculum into the English multilingual setting. SAALT Journal for Language Teaching, 27(4), 269-277. 
Bosman, N. (2000). South Africa's culture of non-learning - a by-product of non-mother tongue education? SAALT Journal for Language Teaching, 34(3), 221-228.

Cele, N. (2001). Oppressing the oppressed through language liberation: repositioning English for meaningful education. Perspectives in Education, 19(1), 181-193.

Cencus in Brief, 2001. http://www.css.gov.za/censuspr/population.htm. Accessed on 6 November 2011.

Coufal, K.L. (1993). Collaborative consultation for speech-language pathologists. Topics in Language Disorders, November, 1-14.

Crutchley, A., Botting, N. \& Conti-Ramsden, G. (1997). Bilingualism and specific language impairment in children attending language units. European Journal of Disorders of Communication, 32, 267-276.

Cunningham, D. (2001). Languages, technology and teaching: challenges and solutions for the $21^{\text {st }}$ century. SAALT Journal for Language Teaching, 35(4), 201-222.

Dawber, A. \& Jordaan, H. (1999). Second Language Learners in the Class-room. Southdale, MN: Aneene Dawber \& Heila Jordaan.

De Klerk, V. (2002a). Language issues in our schools: whose voice counts? Part 1: the parents speak. Perspectives in Education, 20(1), 1-14.

De Klerk, V. (2002b). Part 2: The teachers speak. Perspectives in Education, 20(1), 15-27.

Delport, C.S.L. \& De Vos, A.S. (2002). Professional research and professional practice. In De Vos, A.S. (Ed.). Research at Grass Roots. For the Social Sciences and Human Service Professionals. ( $\left.2^{\text {nd }} e d.\right)$. Pretoria: Van Schaik.

Dougherty, M. (2009). Psychological consultation and collaboration in school and community settings. ( $5^{\text {th }}$ ed). Belmont, CA: Brooks/Cole, Cengage Learning.

Driscoll, A. \& Nagel, N.G. (2002). Early Childhood Education. Birth - 8. Boston, MA: Allyn and Bacon.

Du Plessis, S. (2005). Multilingual preschool learners: A collaborative approach to communication intervention. Unpublished DPhil dissertation. Pretoria: University of Pretoria.

Du Plessis, S. (1998). Spanfunksionering in 'n preprimêre program vir kommunikasiegestremde kleuters. Unpublished M.Communication Pathology Dissertation. Pretoria: University of Pretoria.

Du Plessis, S. \& Louw, B. (2008). Challenges to preschool teachers in learners' acquisition of English as Language of Learning and Teaching. South African Journal of Education, 28(1), 53-75.

Du Plessis, S \& Naudé, E. (2003). The needs of teachers in preschool centres with regard to multilingual learners. South African Journal of Education, 23(2), 122-129.

Ehren, B. J. \& Ehren, T.C. (2001). New or expanded literacy roles for speech-language pathologists: Making it happen in the schools. Seminars in Speech and Language, 22(3), 233-241. 
Ehren, T.C. \& Whitmire, K.A. (2005). Leadership opportunities in the context of responsiveness to intervention activities. Topics in Language Disorders, 25(2), 168- 179 .

Ehren, B.J., Montgomery, J., Rudebusch, J. \& Whitmire, K. 2009. Responsiveness to intervention: New roles for speech-language pathologists. American SpeechLanguage-Hearing Association. http://www.asha.org/members/slp/schools/profconsult/NewRolesSLP.htm. Accessed on 5 September 2011.

Fujiki, M., Brinton, B., Isaacson, T. \& Summers, C. (2001). Social behaviors of children with language impairment on the playground: a pilot study. Language, Speech and Hearing Services in Schools, 32, 101-113.

Gumbo, M.T. (2001). Multicultural education and its politics. South African Journal of Education, 21(2), 233-241.

Hadley,P.A., Simmerman,A., Long,M. \& Luna,M. 2000. Facilitating language development for inner-city children. Experimental evaluation of a collaborative classroom-based intervention. Language, Speech and Hearing Services in Schools, 31: $280-295$.

Heugh, K. (2008). Language policy and education in Southern Africa. Encyclopaedia of Language and Education. www.springerlink.com/content/p62640m146m43525/. Accessed on 23 August 2011.

Holmarsdottir, H.B. (2009). Cultural identity and implementing a new Language-inEducation Policy in South African schools. Globalisation, Comparative Education and Policy Research. www.springerlink.com/content/v545n4rp30465726/. Accessed on 23 August 2011.

Hornberger, N. \& Vaish, V. (2009). Multilingual language policy and school linguistic practice: Globalization and English language teaching in India, Singapore and South Africa. Compare: A Journal of Comparative and Interventional Education, 39(3), 305-320.

Jordaan, H. (1993). Language intervention to facilitate the acquisition of English as a second language by pre-school children. Unpublished MA Speech-Language Pathology Dissertation. Johannesburg: University of the Witwatersrand.

Kamwangamalu, N.M. (2008). Second and foreign language learning in South Africa.

Encyclopaedia of Language and Education. www.springerlink.com.content/ k552u42273w6234W/. Accessed on 23 August 2011.

Laing,S.P. \& Kamhi,A.2003. Alternative assessment of language and literacy in culturally and linguistically diverse populations. Language, Speech and Hearing Services in Schools, 34: 44-55.

LANGTAG. (1996). Towards a National Language Plan for South Africa. Final Report of the Language Plan Task Group, presented to the Minister of Arts, Culture, Science and Technology.

Lazar, C.1994. A review and appraisal of current information on speech/language alternative service delivery models in schools. Communiphon, 308: 8-11. 
Leedy, P.D. \& Ormrod, J.E. (2005). Practical Research. Planning and Design (8th ed.). Upper Saddle River, NJ: Pearson Education.

Le Grange, L. (2002). Educational research, democracy and praxis. South African Journal of Education, 22(1), 36-39.

Lemmer, E.M. (1995). Selected linguistic realities in South African schools: problems and prospects. Educare, 24(2), 82-96.

Lewis, F.2004. Curriculum integration and curriculum innovation - challenges to the school speech-language therapist of today. Communiphon, 337: 36-37.

Macdonald, C. (1991). Eager to Talk and Learn and Think. Bilingual Primary Education in South Africa. Cape Town: Maskew Miller Longman.

Manolson, A. (1992). It Takes Two to Talk. Toronto: The Hanen Centre.

Morsink, C.V. (1991). Framework and rationale for interactive teaming in Morsink, C.V., Thomas, C.C. and Correa, V.I. (Eds). Interactive Teaming. Consultation and Collaboration in Special Programs. New York: Merrill.

NAEYC. (1996). Position statement: Responding to linguistic and cultural diversity recommendations for effective childhood education. Young Children, 51(2), 9-12.

Nel, N. \& Müller, H. (2010). The impact of teachers' limited English proficiency on English second language learners in South African schools. South African Journal of Education, 30, 635-650.

Obondo, M.A. (2007). Tension between English and mother tongue teaching in postcolonial Africa. International Handbook of English Language Teaching. www. springerlink.com/content/h5056123k8785341/. Accessed on 23 August 2011.

Obondo, M.A. (2008). Bilingual education in Africa: An overview. Encyclopaedia of Language and Education. www.springerlink.com/content/n3pmx151V4872866/. Accessed on 23 August 2011.

Owens, R.E.(Jr). (2008). Language Development. An Introduction. (7th ed). Boston, MA: Pearson Education.

Palikara, O., Lindsay, G., Cullen, M.A. \& Dockrell, J. (2007). Working together: The practice of educational psychologists and speech and language therapists with children with specific speech and language difficulties. Educational and Child Psychology, 24(4), 77-88.

Peirce, B.N. \& Ridge, S.G.M. (1997). Multilingualism in Southern Africa. Annual Review of Applied Linguistics, 17, 170-190.

Prelock,P.A.2000. Multiple perspectives for determining the roles of speech-language pathologists in inclusionary classrooms. Language, Speech and Hearing Services in Schools, 31: 213-218.

Probyn, M. (2008). Policy, practice and power: Language ecologies in South African classrooms. Encyclopaedia of Language and Education. www.springerlink.com/ content/nn25k23450705554/. Accessed on 23 August 2011. 
Roseberry-McKibbin, C. \& Brice, A. (2000). Acquiring English as a second language. The ASHA Leader, 5(12), 4-7.

RSA (1996). Constitution of the Republic of South Africa: Act No 108, 1996. Cape Town: Government Printer.

RSA (2001). Education White Paper 5 on Early Childhood Education. Pretoria: Department of Education.

Sadiki, M. (2002). Mother tongue, other tongue and "another tongue". Paper presented at the $14^{\text {th }}$ International English Academy Conference: Mother Tongue, Other Tongue? Law, Learning and Literature. Pretoria. April 2002.

SASLHA, (2003). Working with bilingual populations in speech-language pathology. SASLHA, March 2003, Ethics and Standards Committee.

Smit, B. (1993). Language planning for a future South African educational system: the German language scenario - pedagogical issues. SAALT Journal for Language Teaching, 27(2), 155-166.

Soudien, C. (2007). The "A" factor: Coming to terms with the question of legacy in South African education. International Journal of Educational Development. 27(2), 182-193.

Steyn, J.C. (2000). Quality education and equality in education: a dilemma for democratic South Africa. South African Journal of Education, 20(1), 46-49.

Vandeyar, S. (2010) .Responses to South African teachers to the challenge of school integration. South African Journal of Education, 30, 343-359.

Van Wyk, B. (2010). Learner diversity and learning: A perspective from South Africa.

International conference on learner diversity 2010. www.sciencedirect.com. Accessed on 24 August 2011.

Viljoen, C.F. \& Molefe, R.M.L. (2001). Language related problems of limited English proficiency learners in Grade 1. South African Journal of Education, 21(2), 121-127.

Wilcox,M.J. and Shannon,M.S.1996. Early Intervention practices in speech-language pathology. In McWilliams, R. (Ed). Rethinking Pull-Out Services in Early Intervention. A Professional Resource. Baltimore: Paul H. Brookes Publishing Co.

Uys, M., Van der Walt, J., Van den Berg, R. \& Botha, S. (2007). English medium of instruction: A situational analysis. South African Journal of Education, 27(1), 69-82. 